\title{
Oil Market Shocks and Financial Instability in Asian Countries
}

Fakhri J. Hasanov and Leila Dagher 


\section{Acknowledgments}

We thank Chay Allen for this edits. The views expressed in this paper are those of the authors and do not necessarily represent the views of their affiliated institutions.

\section{About KAPSARC}

The King Abdullah Petroleum Studies and Research Center (KAPSARC) is a non-profit global institution dedicated to independent research into energy economics, policy, technology and the environment across all types of energy. KAPSARC's mandate is to advance the understanding of energy challenges and opportunities facing the world today and tomorrow, through unbiased, independent, and high-caliber research for the benefit of society. KAPSARC is located in Riyadh, Saudi Arabia.

This publication is also available in Arabic.

\section{Legal Notice}

(c) Copyright 2021 King Abdullah Petroleum Studies and Research Center ("KAPSARC"). This Document (and any information, data or materials contained therein) (the "Document") shall not be used without the proper attribution to KAPSARC. The Document shall not be reproduced, in whole or in part, without the written permission of KAPSARC. KAPSARC makes no warranty, representation or undertaking whether expressed or implied, nor does it assume any legal liability, whether direct or indirect, or responsibility for the accuracy, completeness, or usefulness of any information that is contained in the Document. Nothing in the Document constitutes or shall be implied to constitute advice, recommendation or option. The views and opinions expressed in this publication are those of the authors and do not necessarily reflect the official views or position of KAPSARC. 


\section{Key Points}

We examine the relationship between oil market shocks and financial instability in Asian countries.

Structural vector autoregression is applied to data covering 1999M02-2018M03 using Kilian's (2009) methodology framework.

Instability in Asian financial markets is measured by the Financial Stress Index (FSI), as its advantages include detecting stress from different market segments (banking, stock market, foreign exchange, etc.).

We find the following results.

The Asian FSl's response to an oil price shock is negative and statistically significant four to six months after the shock.

The response of oil prices to a stress shock in the FSI is statistically insignificant.

The FSI response to the oil supply shock is mostly not statistically significant but is positive and statistically significant in three intermittent months.

A shock in Asian financial markets has a one-month statistically significant negative effect on crude oil supply.

The findings are useful for international and domestic (net oil exporters and net oil importers) investors for portfolio diversification and other investment-production purposes. They will also help financial stability regulators, such as central bankers and other monetary authorities, to regulate financial markets. 


\section{Introduction}

$\mathrm{T}$ There is no commodity whose interlinkages with the macroeconomy have been studied as extensively as oil, starting with Hamilton's (1983) seminal study. Thousands of subsequent studies have examined the relationship between oil prices and various economic variables, including the stock market. This strand of the literature began with the pioneering work of Kling (1985). Since then, other financial markets, such as banking, have also received a fair share of analysis.

Although the stability of financial markets has been monitored for decades, it has gained much more attention since the 2008 global financial crisis (GFC). A major limitation of previous studies is their use of a proxy for one financial sector while disregarding others. Nazlioglu, Soytas, and Gupta (2015) argue that the Financial Stress Index (FSI) is a better representative of stress in financial markets than indexes based on single markets, such as the Chicago Board Options Exchange's CBOE Volatility Index (VIX), due to its comprehensive coverage of dimensions through which financial stress can arise. We address this limitation by using the FSI. While the first FSI was constructed in 2003 (Illing and Liu 2003), the vast majority of FSIs were developed after (and perhaps in response to) the GFC. In general, FSIs are based on indicators from various financial markets, including but not limited to the equity market, banking sector, and foreign exchange market. The FSI as a proxy for instability in financial markets has advantages over a proxy for one financial sector or market. First, the FSI accounts for stress in each financial sector, but can also detect stress due to the interdependence and complex interactions of different financial subsectors.

Second, as a composite quantitative measure, the FSI enables an easy comparison of financial fragility among several stress episodes. Among the merits of the present study, we employ two FSIs for Asian countries. This helps obtain more robust results and suggest well-grounded policy recommendations. This study considers the FSI of Association of Southeast Asian Nations (ASEAN) +3 countries and that of the group of developing Asian countries.

The literature has already established that oil market shocks affect financial markets in most countries (e.g., Basher, Haug, and Sadorsky 2018; Chen, Hamori, and Kinkyo 2014). Research on the linkages between the financial market and oil market shocks is important, as the findings can be used by international and domestic investors for portfolio diversification and other purposes. These findings are also helpful for financial stability regulators, such as central bankers and other monetary authorities regulating financial markets. However, to the best of our knowledge, no empirical study establishes the relationships between different oil market shocks and the FSI of Asian countries. This is the objective of the present study.

Following the seminal studies in this domain, such as Kilian (2009) and Kilian and Park (2009), we apply structural vector autoregression (SVAR) to monthly data of Asian countries' FSIs, oil market indicators of global oil production, and oil prices alongside global economic activity over 1999M02-2018M03. We find that the shocks to Asian financial markets have negative effects on crude oil supply and world economic activity, while we do not find any statistically significant impact on the oil price. In addition, we find that the Asian FSIs respond negatively to oil-specific demand shocks. Their response to oil supply shocks mainly is not statistically insignificant, although the response is positive and statistically significant in the third, sixth and eighth months after the shock. Furthermore, the responses of the FSIs to the shocks to world economic activity are insignificant in general. Our findings are in line with those of previous studies and are consistent with the nature of the Asian 
FSI. The findings are almost the same regardless of which measure of FSI is considered, suggesting robustness of the results.

The remainder of the paper proceeds as follows.

Section 2 presents a review of the relevant literature.

Section 3 provides an exposition of the data.
Section 4 outlines the econometric methodology. The empirical analysis is presented in Section 5. The findings are discussed in Section 6. Finally, we provide concluding remarks in Section 7. 


\section{Literature Review}

$\mathrm{T}$ The literature investigating the effects of oil price shocks on the economy and on financial markets is immense and growing. In the last decade, the approach of Kilian (2009) and Kilian and Park (2009) has attracted a great deal of attention. ${ }^{1}$ Earlier studies investigated oil price changes while holding all other variables constant (assuming that oil prices were exogenous), which is not accurate in real life. Moreover, these studies investigated oil price shocks without defining their origin or source. Kilian's (2009) framework allows for four types of shocks: political oil supply shocks, other oil supply shocks, aggregate demand shocks, and oil-specific demand shocks. His findings confirm that the source of the shock driving an oil price increase is crucial in assessing how it affects United States (U.S.) gross domestic product (GDP) and inflation.

Using the same framework, Kilian and Park (2009) add the returns to the country's stock market index as a variable in vector autoregression (VAR). The findings show that the responses of aggregate U.S. real stock returns differ greatly, depending on whether the increase in the price of crude oil is driven by global oil-specific demand shocks or by global supply shocks in the crude oil market.

\subsection{Oil shocks and financial markets}

Since these seminal contributions, a plethora of studies has employed Kilian's (2009) and Kilian and Park's (2009) approach when studying oil price shocks' effects on various sectors. We focus on the stream of literature looking specifically at the financial sector ${ }^{2}$ (stock markets, exchange rates, etc.) in one or more countries in our sample.

Similarly to Kilian (2009) and Kilian and Park (2009), numerous studies have looked at stock markets around the world and their response to oil price shocks. The findings have been mixed. Apergis and Miller (2009) investigate eight developed economies, including Japan, which we also examine in this study. Based on a variance decomposition analysis, all three shocks (oil supply, aggregate demand, and oil demand) combined have a minor impact on stock markets in Japan. Causality tests also show no significant causality in any direction. Other studies mentioned below perform impulse response analyses and obtain interesting results. We are particularly interested in the findings of impulse response functions in terms of significance, sign and persistence, for comparison with our findings.

Basher, Haug, and Sadorsky (2012) look at emerging markets (using the Emerging Markets EM-MSCl index, which includes seven Asian countries $^{3}$ from our sample) and find that positive shocks to oil prices tend to slightly and transiently (one month) depress emerging market stock prices (and exchange rates) with a one-month lag. Meanwhile, a positive shock to the stock market results in an increase in oil prices lasting for around six months. The result that increased oil prices have a negative effect on stock market prices is supported by Abhyankar, Xu, and Wang's (2013) empirical study on Japan, but starting around five or six months after the shock and lasting longer. Wang, $\mathrm{Wu}$, and Jin (2013) find insignificant results for Japan, Korea, and India. However, for China, they find that the stock market significantly declines nine months after the oil price shock.

By contrast, Bai and Koong (2018) find that the Chinese stock market (Shanghai Composite Index) responds positively to a positive oil price shock, while the response of oil prices to a stock market shock is insignificant. A similar result is found by Fang and You (2014) for India lasting only for one month, while China's stock returns respond negatively to a positive price shock for between three and six months. 
In summary, there is no consensus in the literature on the direction, magnitude, or significance of oil price shocks on Asian stock market returns.

Instead of looking at one financial subsector, one can use an FSI that incorporates indicators from various financial sub-sectors, namely, the stock market, banking sector, and exchange rate market. It captures different dimensions of stress in financial markets, as mentioned in the previous section.

Using different approaches, several studies have used some measures of FSI for the U.S. to explore the oil price shock-financial stability nexus. These studies include, inter alia, Nazlioglu, Soytas, and Gupta (2015), who use the Federal Reserve of Cleveland FSI; Das et al. (2018), who use the Federal Reserve Bank of St. Louis FSI; Chen, Hamori, and Kinkyo (2014) and Qadan and Nama (2018), who use the Kansas City FSI; Morana (2013), who uses the U.S. Financial Fragility Index; and Wan and Kao (2015), who use the National Financial Conditions Index. The findings of these studies are not unanimous.

For the rest of the world, El Shal (2012) uses the Egyptian FSI, while Cashin, Mohaddes, and Raissi (2017) construct a global FSI for 26 countries.

They discover that the fit of the model improves significantly when they include the FSI, as it captures the effect of the global financial cycle, something usually overlooked in other studies.

Based on the literature survey, and to the best of our knowledge, no empirical study examines the relationships between oil market-related shocks and the FSI of Asian countries. Therefore, this study aims to fill this significant gap given the global importance of Asian countries such as Japan, South Korea, China, and India. 


\section{Data}

W e use monthly time-series data over the period 1997M01-2018M03 for the variables presented below. The period is decided upon based on data availability.

Financial Stress Index. This is our variable of interest, that is, the dependent variable. We use two measures of the FSI in this study.

Financial Stress Index for ASEAN+3 (FSI_AP). This is the FSI developed for the ASEAN countries, Japan, South Korea, and China. ASEAN countries are Brunei, Cambodia, Indonesia, Laos, Malaysia, Myanmar, Philippines, Singapore, Thailand and Vietnam.

\section{Financial Stress Index for Developing Asia} (FSI_DA). This is the FSI for the group of developing Asian countries, which are Bangladesh, Bhutan, Brunei, Cambodia, China, Fiji, India, Indonesia, Kiribati, Laos, Malaysia, Maldives, Marshall Islands, Mongolia, Myanmar, Nepal, Palau, Philippines, Samoa, Solomon Islands, Sri Lanka, Thailand, Timor-Leste, Tonga, Tuvalu, Vanuatu and Vietnam.

Both indexes are constructed using the methodology of Park and Mercado (2014). Both series have been updated until March 2018 and are available from the Asia Regional Integration Center's website (https:// aric.adb.org/database/fsi). Park and Mercado (2014) follow the methodology of Balakrishnan et al. (2009, 2011), Cardarelli, Elekdag, and Lall $(2008,2011)$, and Yiu, Ho, and Jin (2010) in constructing the indexes. Each index is a composite indicator that represents four major financial sectors: the banking sector, foreign exchange market, equity market, and debt market.
Real Oil Price (OPR_B). This is the Europe Brent free on board (FOB) spot price of crude oil in 2015 U.S. dollars per barrel. Nominal values of the oil price are downloaded from the U.S. Energy Information Administration's (EIA's) official website under the spot prices category and deflated using the U.S. Consumer Price Index (CPI). The U.S. CPI is the total of all items for the U.S., index $2015=100$, monthly or seasonally adjusted and retrieved from the OECD via FRED Economic Data (https://fred. stlouisfed.org/series/CPALTT01USM661S).

World Crude Oil Production (OPRD_W). This is the total world petroleum production measured in million barrels per day. The data are from the official website of the EIA under the supply breakdown of the category labelled " $3 a$. International Petroleum and Other Liquids Production, Consumption, and Inventories."

World Real Economic Activity (GDP_W). This is the real world GDP index, 2015M2=100. The data are from the EIA's official website under the category labelled " $3 \mathrm{~d}$. World Petroleum and Other Liquids Consumption."

Figure 1 illustrates the time trajectories of the variables for the period 1997M01-2018M03. 

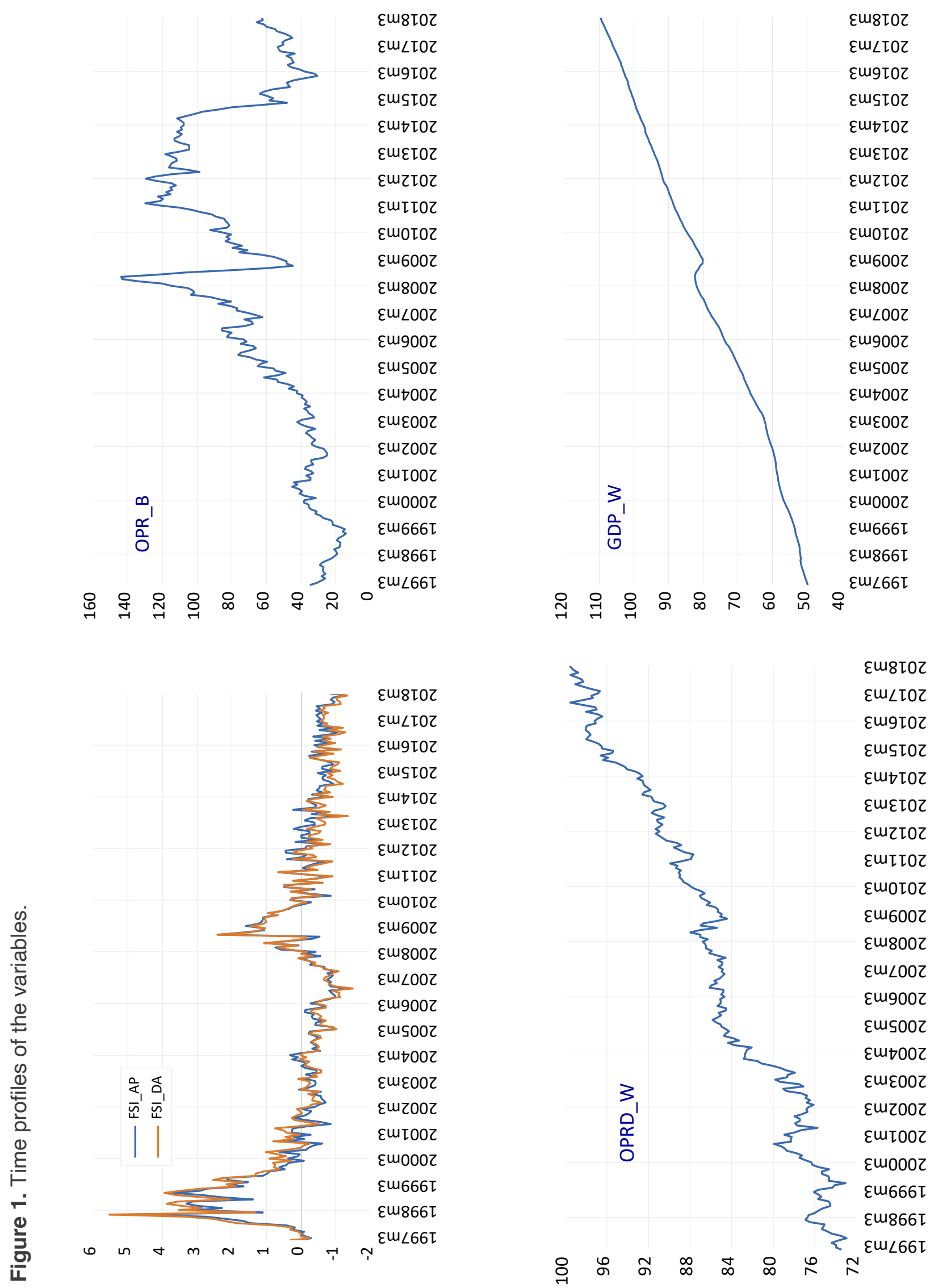


\section{Econometric Methodology}

O ur empirical analysis starts by testing the non-stationary properties of the variables employed. Socio-economic as well as energy and financial variables usually demonstrate non-stationary behavior over time. If this is not taken into consideration, the estimation results and, thus, the conclusions and policy recommendations too, may be invalidated. We use the augmented Dickey-Fuller (ADF) (Dickey and Fuller 1981) test for this purpose. Enders and Lee (2012b) find that Dickey-Fuller-type unit root tests outperform other conventional tests, as the former do not have initial value issues. We also use unit root tests that address structural breaks in the data in case the ADF does not provide reasonable results. For this purpose, we can use the Fourier approximation augmented ADF developed by Enders and Lee (2012b), which outperforms other unit root tests addressing structural breaks. Enders and Lee (2012a, 2012b) demonstrate the superiority of their test compared with other counterparts.

Following earlier studies, we employ SVAR in our empirical assessments and use the natural logarithmic levels (or first differences of those logarithmic levels) of the variables where possible (e.g., Kilian 2009; Kilian and Park 2009; Chen, Hamori, and Kinkyo 2014). The following section describes the SVAR and the forms of the variables used and assumptions/restrictions made. 


\section{Empirical Analysis}

\subsection{Unit root testing}

Before proceeding to the unit root test results, we briefly discuss the data. As Figure 1 illustrates, both the FSI measures, FSI_DA and FSI_AP roughly range between -2 and 6 . Given that they take negative values and their values are numerically small, we use their levels and not the natural logarithm expressions in the unit root test. We use the natural logarithmic expression of the remaining variables and denote them in lowercase letters, namely, opr_b, oprd_w, and $g d p \_w$. Kilian (2009) and Chen, Hamori, and Kinkyo (2014) use 24 lags as the maximum lag order for their monthly data. It is standard in the literature to consider 24 lags for monthly data (eight lags for quarterly data and two lags for annual data). Thus, we set the maximum lag order to 24. The maximum lag length and taking the first difference of the variables for unit root tests and estimation truncate our sample to start in 1999M02. We select the optimal lag length in the tests and estimations based on the Schwarz information criterion.

Table 1 presents the ADF unit root test results for the variables.

Table 1. UR test results.

\begin{tabular}{|c|c|c|c|c|c|}
\hline \multirow[t]{2}{*}{ Variable } & \multicolumn{5}{|l|}{ ADF test } \\
\hline & Test value & C & $t$ & $\mathrm{~N}$ & $k$ \\
\hline$F S I \_A P$ & -2.64 & & $x$ & & 3 \\
\hline$F S I \_D A$ & -2.90 & & $x$ & & 2 \\
\hline$o p r \_b$ & -1.67 & $x$ & & & 1 \\
\hline$g d p \_w$ & -1.83 & & $x$ & & 2 \\
\hline oprd_w & $-3.85^{\star \star}$ & & $x$ & & 0 \\
\hline$\triangle F S I \_A P$ & $-13.66^{\star \star \star}$ & & & $x$ & 2 \\
\hline$\triangle F S I \_D A$ & $-16.48^{\star \star \star}$ & & & $x$ & 1 \\
\hline$\Delta o p r \_b$ & $-13.18^{\star * \star}$ & & & $x$ & 0 \\
\hline$\Delta g d p \_w$ & $-4.38^{\star \star \star}$ & $x$ & & & 1 \\
\hline$\Delta o p r d \_w$ & $-14.07^{\star \star *}$ & $x$ & & & 1 \\
\hline
\end{tabular}

Notes: ADF denotes the augmented Dickey-Fuller test. The maximum lag order is set to 24 , and the optimal lag order ( $k$ ) is selected based on the Schwarz criterion in the tests. ${ }^{* *},{ }^{* *}$, and * indicate rejection of the null hypotheses at the $1 \%, 5 \%$, and $10 \%$ significance levels, respectively. The critical values for the ADF are taken from MacKinnon (1996). The final UR test equation includes one of three options: intercept $(\mathrm{C})$, intercept and trend $(t)$, and none $(\mathrm{N})$. $\mathrm{x}$ indicates that the corresponding option is selected in the final URT equation based on statistical significance. 
The ADF test sample values cannot reject the null hypothesis of the unit root process for FSI_AP, $F S I \_D A, o p r \_b$, and $g d p \_w$ but can reject it for their first differences at the $1 \%$ significance level. These results suggest that the variables are unit root processes at their levels and stationary at their first differences. In other words, FSI_AP, FSI_DA, opr_b, and $g d p \_w$ are I(1) processes.

The ADF test results indicate that oprd_w is a trend-stationary process at the $5 \%$ significance level but a unit root process at the $1 \%$ significance level. The graphical illustration of the variable in Figure 1 suggests more of a stochastic than a deterministic trend for the variable (e.g., the trend in the oprd_w profile is not as deterministic as that in the $g d p \_w$ profile). In addition, the coefficient on the lagged level dependent variable, oprd_wt-1, in the ADF test equation of oprd_w is -0.11 . Hence, the autoregressive coefficient becomes $0.89(-0.11+1)$, which is more in favor of a unit root process than a stationary process. Moreover, we apply the EL test to $o p r d \_w$ series, as the variable may have structural break(s) and thus, non-linearity in its development trend. ${ }^{4}$ We find that there are no structural breaks or non-linear trends in the data-generating process of $o p r d \_w$. Therefore, we can use and rely on the results of the conventional ADF test, as suggested by Enders and Lee (2012b). To this end, we conclude that $o p r d \_w$ is a unit root process. Since the ADF sample value suggests profoundly that the first difference of oprd_w is stationary, we consider it as an I(1) variable.

Thus, we conclude that our variables are unit root processes at their level or log level, but their first differences are a stationary process. In other words, they are I(1) variables.

\subsection{SVAR analysis}

We use the stationary transformations of our variables in constructing an SVAR to estimate impulse response functions following the standard literature (e.g., Kilian and Park 2009; Kilian 2009; Chen, Hamori, and Kinkyo 2014)..$^{5}$ Our SVA is expressed as

$$
A_{0} X_{t}=\alpha+\sum_{i=1}^{k} A_{i} X_{t-i}+\varepsilon_{t}
$$

Here, $X_{t}=\left(\Delta o p r d \_w_{t}, \Delta g d p \_w_{t}, \Delta o p r_{-} b_{t}, \Delta F S I_{t}\right)^{\prime}$. $\triangle F S I_{t}$ is represented by $\triangle F S I_{-} A P_{t}$ and $\triangle F S I_{-} D A_{t}$ at a time and hence, we estimate two SVARs. $\boldsymbol{k}$ is the maximum number of lag orders, which equals 24, following Kilian and Park (2009), Kilian (2009), and Chen, Hamori, and Kinkyo (2014). The reason for choosing a 24-month lag order is to capture potential two-year effects of structural oil price shocks on the other variables, as explained by Chen, Hamori, and Kinkyo (2014). $A_{0}$ is a matrix of the contemporaneous coefficient and $A_{i}$ is a matrix of the coefficients on the lagged variables. $a$ is the vector of the constant terms. $\varepsilon_{t}$ is a vector of serially and mutually uncorrelated structural shocks.

If we denote by $e_{t}$ the innovations of the reduced-form VAR and $e_{t}=\varepsilon_{t} A_{0}{ }^{-1}$, then the structural innovations can be obtained from the reduced-form innovations by imposing exclusion restrictions on the $A_{0}{ }^{-1}$ matrix. Different restrictions can be applied, and we assume that the contemporaneous relationship between the reduced-form innovations and the structural innovators is recursive, that is, Cholesky lower triangular. This can be written as

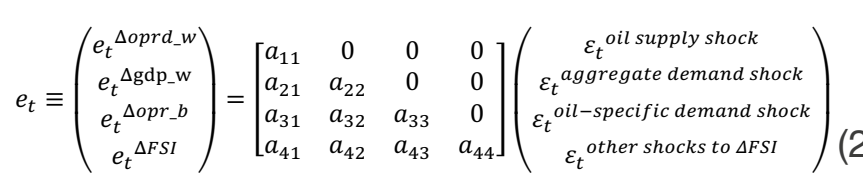


The reason for assuming a recursive relationship is because of the nature of the relationships among our variables, as explained below.

The first shock denotes the oil supply shock resulting from production disruptions due to political frictions (e.g., conflicts in the Middle East) (Bastianin and Manera 2018), wars, or changes in OPEC supply quotas (Abhyankar, Xu, and Wang 2013). This type of shock affects the three remaining variables but does not react in the same period to any of the other innovations. The argument here is that oil supply does not respond quickly to changes in oil markets, given that production levels are set based on specific medium-term demand and it would be very costly to make short-run changes.

The second shock is the aggregate demand shock that captures changes in the demand for all industrial commodities (including crude oil) driven by global economic activity. This type of shock affects the remaining two variables but reacts contemporaneously only to the oil supply shock. The reason that oil-market-specific demand shocks do not seem to affect global economic activity instantaneously is because of a lack of empirical evidence of any immediate feedback from changes in the real price of oil (Kilian, 2009; Kilian and Murphy, 2012; Abhyankar et al., 2013). Hence, any influence will be delayed. Furthermore, given the sluggishness of real economic activity, it does not respond within the month to changes in the real price of oil.

The third shock denotes the oil-market-specific demand shock (also known as a precautionary demand shock), which is due to unexpected changes in oil prices. This shock influences financial markets and is itself affected contemporaneously by the previous two shocks.
Finally, the FSI is affected contemporaneously by all three previous shocks, since financial markets react rather speedily to changes in macroeconomic news and events (Bai and Koong 2018). However, for obvious reasons, its innovations have a lagged effect on the previous three variables.

As mentioned above, we estimate two SVARs, as we have two FSI measures. We first specify an unrestricted VAR with the endogenous variables ordered as $\left(\Delta o p r d_{-} w_{t}, \Delta g d p_{-} w_{t}, \Delta o p r_{-} b_{t}, \Delta F S I_{t}\right)$, and the exogenous variables of intercept and a pulse dummy variable. $\Delta F S I_{t}$ is represented by $\triangle F S I_{-} A P_{t}$ and $\triangle F S I_{-} D A_{t}$. The dummy variable takes one in 1998M11 and zero otherwise, with the intent of capturing a huge increase in both the FSIs caused by the GFC, as illustrated in Figure 1. The unrestricted VARs are estimated with the maximum lag order of 24, as discussed above, and it appears that the lag order can be reduced to 20 lags while maintaining the required residual properties. The VARs with 20 lags also meet the stability condition and their residuals do not have other issues, as Table 2 documents. ${ }^{6}$

Lastly, using the $A_{0}{ }^{-1}$ matrix, we transform the unrestricted VARs to SVARs and perform the impulse response analysis. Figures 2 and 3 illustrate the impulse responses of the SVAR1 and SVAR2, where $\triangle F S I_{t}$ is represented by $\triangle F S I_{-} A P_{t}$ and $\triangle F S I_{-} D A_{t}$, respectively. 
Table 2. VAR residual diagnostics and stability test results.

SVAR1

\begin{tabular}{lcc}
\multicolumn{3}{l}{ Panel A: Serial correlation LM test } \\
\hline Lags & LM-statistic & P-value \\
\hline 1 & 10.145 & 0.859 \\
\hline 2 & 19.056 & 0.269 \\
\hline 3 & 15.171 & 0.512
\end{tabular}

Panel B: Normality test ${ }^{\mathrm{b}}$

\begin{tabular}{lccc}
\hline Statistic & $x^{2}$ & d.f. & P-value \\
Skewness & 5.169 & 4 & 0.270 \\
Kurtosis & 45.160 & 4 & 0.000 \\
Jarque-Bera & 50.329 & 8 & 0.000
\end{tabular}

\begin{tabular}{lccc}
\hline Panel C: Heteroscedasticity Test $^{c}$ & & \\
\hline White & $x^{2}$ & d.f. & P-value \\
Statistic & 1670.381 & 1610 & 0.144
\end{tabular}

\section{Panel D: VAR stability condition}

Root

Modulus

$-0.057+0.961 i$

0.962

$-0.057-0.961 i$

0.962

$0.943+0.172 i$
SVAR2

\begin{tabular}{lcc}
\multicolumn{3}{l}{ Panel A: Serial correlation LM test } \\
\\
\hline Lags & LM-statistic & P-value \\
\hline 1 & 7.624 & 0.959 \\
\hline 2 & 18.37 & 0.303 \\
\hline 3 & 19.525 & 0.242
\end{tabular}

Panel B: Normality test ${ }^{\mathrm{b}}$

\begin{tabular}{lccc}
\hline Statistic & $x^{2}$ & d.f. & P-value \\
Skewness & 6.895 & 4 & 0.142 \\
Kurtosis & 44.415 & 4 & 0.000 \\
Jarque-Bera & 51.310 & 8 & 0.000
\end{tabular}

\begin{tabular}{lccc}
\hline \multicolumn{3}{l}{ Panel C: Heteroscedasticity test $^{\mathrm{c}}$} & \\
\hline White & $x^{2}$ & d.f. & P-value \\
Statistic & 1662.324 & 1610 & 0.178
\end{tabular}

\begin{tabular}{lc}
\hline Panel D: VAR stability condition & \\
\hline Root & Modulus \\
$0.941-0.179 i$ & 0.958 \\
$0.941+0.179 i$ & 0.958 \\
$-0.05-0.956 i$ & 0.958
\end{tabular}

Notes: a The null hypothesis in the serial correlation LM test is that there is no serial correlation at lag order $\mathrm{h}$ of the residuals. ${ }^{b}$ The normality test is Lütkepohl's system normality test where the null hypothesis of the residuals is multivariate normal. ${ }^{c}$ The White heteroscedasticity test takes the null hypothesis of no cross-term heteroscedasticity in the residuals; $x^{2}$ is Chi-squared; d.f. means degree of freedom; and P-value means probability value. Although our data range from $1997 \mathrm{~m} 01$ to $2018 \mathrm{m03}$, our SVAR estimations cover the period $1999 \mathrm{m02}$ to $2018 \mathrm{m03}$. The first 24 observations (months) are consumed for optimal lag selection and by taking the first differences of variables to make them stationary. Given that a lag order of 20 is found to be optimal and the SVAR estimations start in 1999m02, the lag effects go back to 1997M06. 

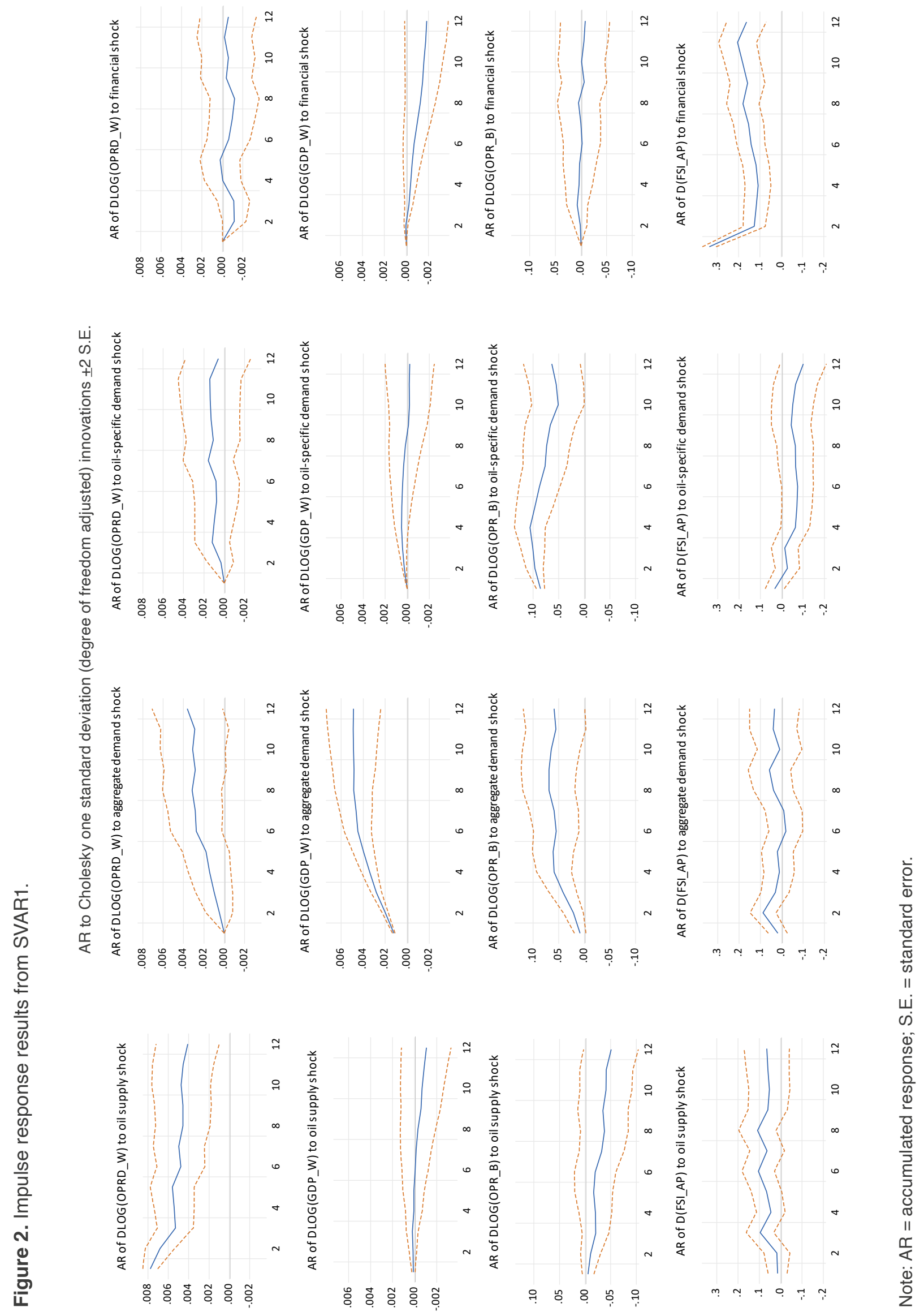


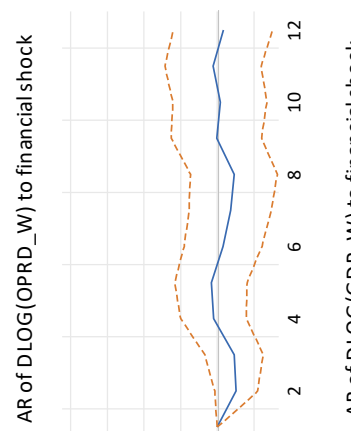

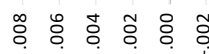

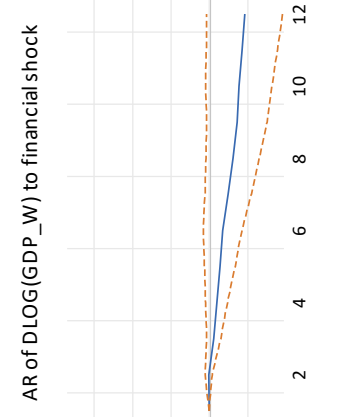

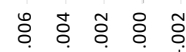
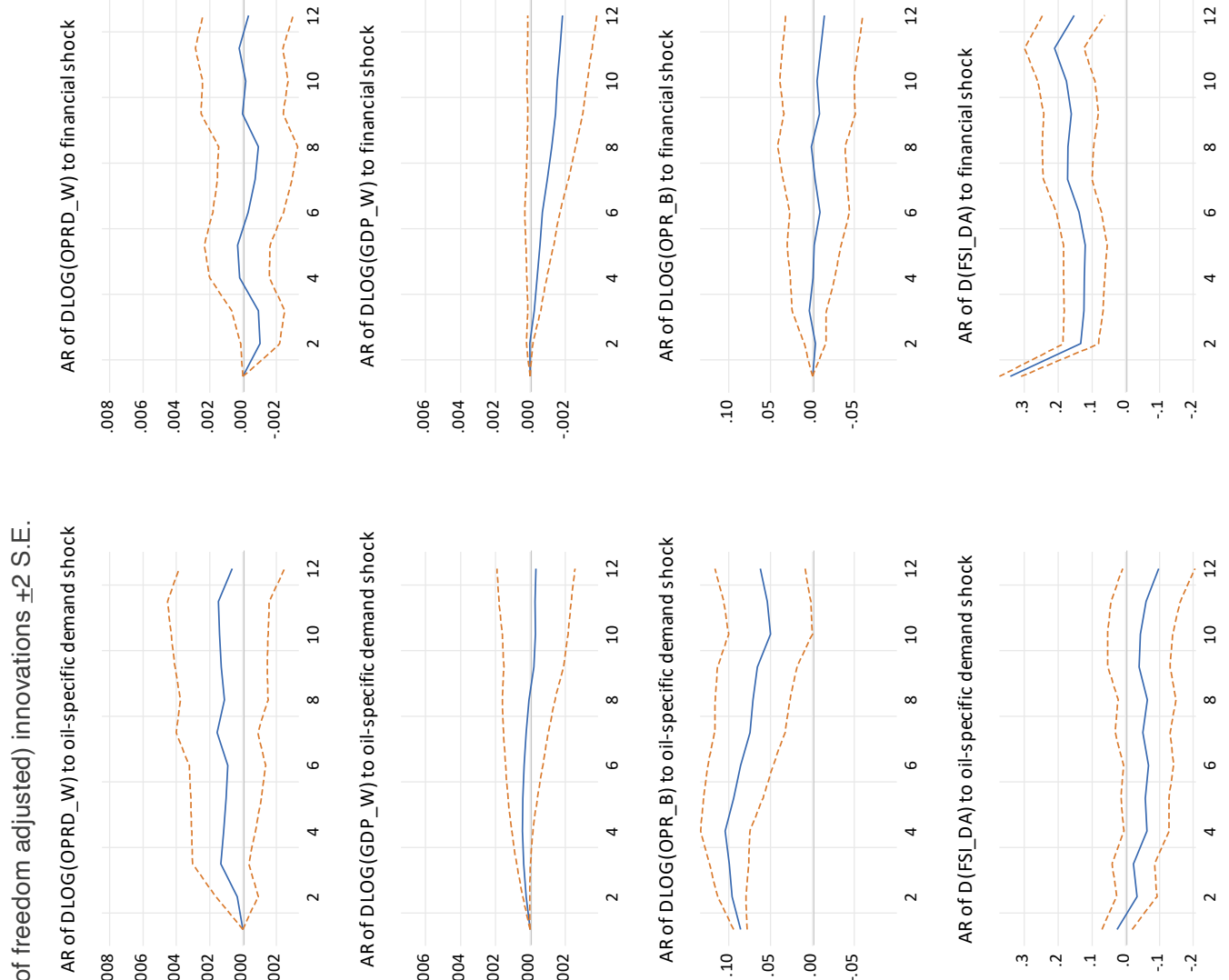

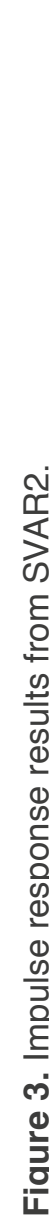
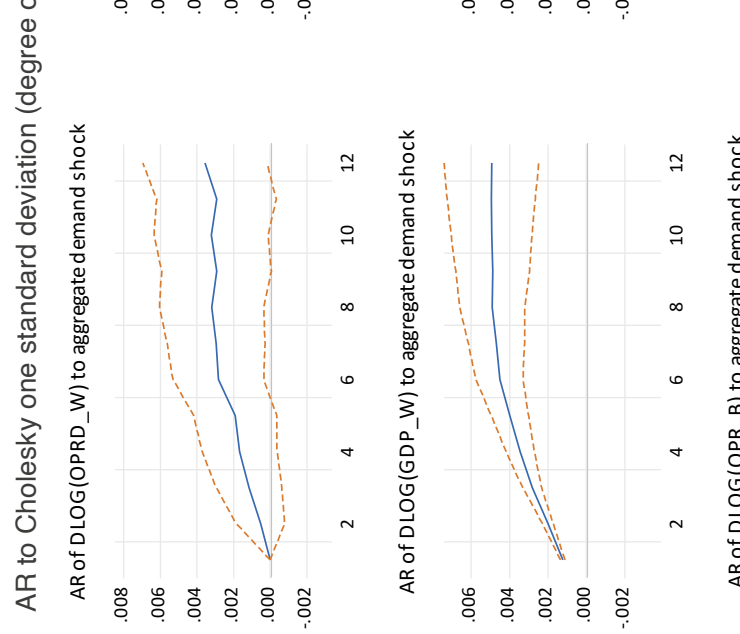

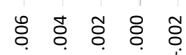

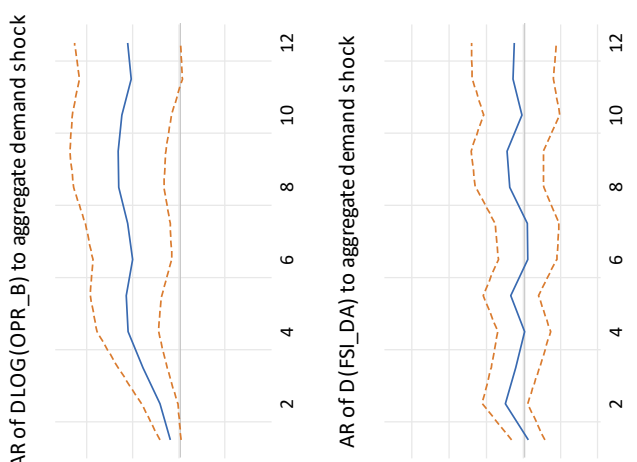

웅 웅

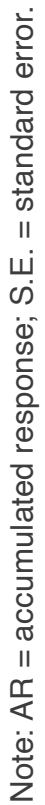




\section{Discussion}

he unit root results in Table 1 show that the variables are non-stationary at their level or

log level but stationary at their first-differenced forms. This finding implies that any kind of shocks to the (log) level of our variables can create permanent changes, such as structural breaks or regime shifts. Examples of such permanent changes can be easily observed from the graphical illustration of the variables in Figure 1. Hence, using the (log) level forms of the variables in the empirical analysis may lead to misleading results unless a theoretically interpretable long-run relationship is established among them. However, the first-differenced forms of the variables are stationary, that is, they follow a mean-reverting process. Hence, any shocks to these forms are temporary, as the processes are restored back to their mean values. Stationary forms of the variables are recommended for use in the empirical analysis, as they follow conventional testing and inferencing. We use stationary forms of the variables in our SVAR analysis here.

The impulse response analysis results of the variables from SVAR1 and SVAR2 are illustrated in Figures 2 and 3 , respectively. It is noteworthy that the results are almost the same regardless of the FSI measure considered. This may indicate that the obtained results are robust. Here, we discuss the results observed in the figures. We start with the FSI and oil price, the main variables of interest. The shocks to financial markets have negative effects on crude oil supply and world economic activity, and these findings are expected. Oil producers lower their production in the second month after the financial markets' shocks. Consequently, world economic activity slows over time, and its negative response to the shocks becomes statistically significant after seven months. Our finding is consistent with that of Chen, Hamori, and Kinkyo (2014). These authors conclude that world economic activity responds to instability in the financial markets negatively, with some delay. Differences in the delay, that is, eight and twelve months after the shock in our study and three and eight months after the shock in Chen, Hamori, and Kinkyo (2014), can be explained by the fact that we use the Asian FSI whereas they use the global FSI. Hence, it seems reasonable that the global FSI has the power to impact world economic activity earlier than the Asian FSI can. It is interesting that they find no statistically significant impact of global financial market instability on crude oil production. However, one can reasonably expect a statistically significant negative effect from the former to the latter through different channels, such as a slowdown in world economic activity, which they find.

In this study, we find no statistically significant impact of Asian financial markets' shocks on the real price of Brent crude oil. Chen, Hamori, and Kinkyo (2014) find that the real oil price has a statistically significant negative reaction to shocks in the global financial market between three and six months after the shock. Both findings seem reasonable, as global financial market instability is expected to have stronger global implications and a wider impact than Asian financial market instability.

Regarding the impacts of the other variables' shock on the FSI, we find that the responses of the latter to oil supply shocks are mainly not statistically significant except in the third, sixth and eighth months after a shock, as Figures 1 and 2 illustrate. In these months, the FSI reacts to the global oil supply shocks positively. Sign-wise, this positive relationship is expected, given that the real oil price is negatively affected by global oil supply shocks. In turn, oil-specific demand shocks negatively affect the FSI, as discussed below (see the second graph in the first column and the third and first graphs in the fourth row of Figures 1 and 2). Chen, Hamori, and Kinkyo (2014) also find that the global FSI 
negatively responds to oil-specific demand shocks. These negative responses can be derived from the positive responses of the real oil price to aggregate demand shocks and the negative responses of global economic activity to Asian financial market shocks, as discussed below.

The responses of the FSI to shocks to world economic activity are insignificant in general. Our findings are consistent with those of Kilian and Park (2009), who also find that responses of the real stock return to world economic activity shocks are statistically insignificant. Meanwhile, their response to oil-specific demand shocks are statistically significant during the second and fourth months after a shock.

Turning to the impulse response interactions between the real oil price and other variables, Figures 1 and 2 illustrate that the responses of the real oil price to oil supply shocks are negative but statistically insignificant. Furthermore, the statistical significance increases toward the end of the horizon. The reaction of the real oil price to world economic activity shocks is positive and statistically significant. These two findings are closely consistent with those of Kilian (2009), Kilian and Park (2009), and Chen, Hamori, and Kinkyo (2014). As mentioned above, we find no statistically significant response of the real oil price to Asian financial market shocks. Whereas Chen, Hamori, and Kinkyo (2014) find that the real oil price demonstrates a statistically significant negative reaction to global financial market shocks between the third and sixth months after the shock. Both results are meaningful, as it is reasonable to expect a statistically significant response of the real oil price to global financial market shocks but not Asian financial market shocks. Regarding the impacts of oil-specific demand shocks, as mentioned above, they have statistically significant negative effects on both FSI measures with delays. This finding is in line with those of Chen, Hamori, and Kinkyo (2014) and Kilian and Park (2009). Oil-specific demand shocks also have statistically significant positive effects on world economic activity during the second and third months after a shock and then become insignificant. This finding perfectly matches that of Chen, Hamori, and Kinkyo (2014). Our finding is also consistent with that of Kilian (2009). We find no statistically significant impacts of real oil price shocks on world oil production, which is the same result as in Kilian (2009). This broadly corroborates the findings of Chen, Hamori, and Kinkyo (2014), as they also find the effect to be statistically insignificant during the 12-month horizon, except in the fourth month.

Moreover, we find that world oil production responds statistically significantly to aggregate demand shocks in a positive way, starting in the sixth month after a shock. This finding is in line with that of Chen, Hamori, and Kinkyo (2014).

As mentioned above, for robustness, we consider two measures of Asian FSI, namely, $F S I_{-} A P_{t}$ and $F S I \_D A_{t}$. We also perform two additional robustness exercises. First, we calculate forecast error variance decomposition for the variable involved in the VAR analyses. Second, we replace the measure of world economic activity with another index of global real economic activity, the Kilian index, obtained from his website, https://sites.google.com/site/lkilian2019/ research/data-sets. The results from these two exercises are very similar to those discussed here, indicating the robustness of the results we reported and discussed above. ${ }^{7}$ 


\section{Conclusion and Policy Insights}

W

e investigate the relationship between

the oil market and financial markets

proxied by the FSI. This is the first study

to explore the relationship between FSIs in Asian countries and oil market shocks. Based on impulse response functions, the findings confirm that the source of an oil price shock (supply side or demand side) matters greatly to its effect on financial markets. While both produce a negative effect on the FSI, the patterns are different; the former is intermittent but lasts longer (up to eight months), while the latter is significant only four to six months after the shock. Moreover, the response of oil prices to a stress shock in the FSI is insignificant.

These findings have a number of policy and practical implications. With the increasing financialization of oil, our contribution provides insights for international investors and portfolio managers. For example, futures contracts or other financial instruments can be used to hedge against demand uncertainty given the negative impact of demand-driven oil price shocks on financial markets. Moreover, the revealed linkages between the global economy and oil markets should be useful to economists and policymakers. When designing a stabilization policy for oil price shocks, policymakers from net oil exporting and importing countries should take the source of the shocks into account.

Future research should investigate each country's FSI separately, as financial markets' interlinkages with oil shocks have been found to be country specific (Bai and Koong 2018; Basher, Haug, and Sadorsky 2018; Broadstock and Filis 2014; Hu et al. 2018). The results may also depend on whether a country is a net oil importer or a net oil exporter (Wang, Wu, and Yang 2013). Country-specific results potentially offer opportunities for portfolio diversification and hence are of interest to portfolio managers. 


\section{Endnotes}

See Kilian and Zhou (2020) for a comprehensive review of the use of VARs in oil markets and Gupta and Modise (2013) for a critical review of the literature.

${ }^{2}$ Other studies use different variables to represent the financial sector, such as the credit default swap market CDX spread (Dai and Serletis 2018) and economic policy uncertainty (Rehman 2018; Kang and Ratti 2015; Kang, de Gracia, and Ratti 2017).

${ }^{3}$ The seven countries are China, India, Indonesia, Korea, Malaysia, the Philippines, and Thailand.

${ }^{4}$ We run the Fourier ADF test equation five times with the frequency of the trigonometric functions changing from one to five, as suggested by Enders and Lee (2012b). We also include intercept and deterministic trends in the equations but no lagged dependent variable, as there is no serial correlation in the residuals of any equation. The sum of squared residuals statistics prefer the equation with frequency of the trigonometric functions of two. We test whether we can assume a non-linear trend or structural breaks in the data-generating process of the variable following the procedures by Enders and Lee (2012b). The F-sample value is 3.74 while F-critical values from Enders and Lee (2012b, Table 1a), in the case of $\mathrm{T}=200$, are $7.62,8.88$, and 11.70 at the $10 \%$, $5 \%$, and $1 \%$ significance levels, respectively. The null hypothesis of the linear trend is not rejected, as the sample value is smaller than any critical value at the different significance levels.

${ }^{5}$ Our analysis here follows Kilian and Park (2009), Kilian (2009), and Chen, Hamori, and Kinkyo (2014). These studies, like many others on the relationships between FSI and energy-macroeconomic variables, use the stationary sequences of variables. Thus, they do not conduct cointegration analysis. From the standpoint of integration-cointegration properties of data, if the variables are I(1), then cointegration analysis should be conducted first (e.g., Banerjee, Arčabić, and Lee [2017] criticize Kilian [2009] in this regard). Again, we do not conduct a cointegration analysis here and aim to address this issue in future research.

${ }^{6}$ The residuals of the VARs are leptokurtic, that is, they have tails that asymptotically approach zero more slowly than a Gaussian. Therefore, they produce more outliers than the normal distribution. Having more outliers is usual for monthly data, which are more volatile than quarterly or annual data. Moreover, Lütkepohl (1991) and Hendry and Juselius (2001) discuss that simulation studies show that statistical inferences from the VAR analysis are sensitive to parameter non-constancy, serially correlated residuals and residuals skewness, while the inferences are moderately robust to excess kurtoses, that is, fat-tailed distribution and residual heteroscedasticity.

${ }^{7}$ The results are not reported here to save space but are available from the authors upon request. 


\section{References}

Abhyankar, Abhay, Bing Xu, and Jiayue Wang. 2013. "Oil Price Shocks and the Stock Market: Evidence from Japan." The Energy Journal 34(2): 199-222. DOI: 10.5547/01956574.34.2.7

Apergis, Nicolas, and Stephen M. Miller. 2009. "Do Structural Oil-market Shocks Affect Stock Prices?" Energy Economics, 31(4): 569-75. DOI: 10.1016/j. eneco.2009.03.001

Bai, Shuming, and Kai S. Koong. 2018. "Oil Prices, Stock Returns, and Exchange Rates: Empirical Evidence from China and the United States." The North American Journal of Economics and Finance 44: 12-33. DOI: 10.1016/j.najef.2017.10.013

Balakrishnan, Ravi, Stephan Danninger, Selim Elekdag, and Irina Tytell. 2009. "How Linkages Fuel the Fire: The Transmission of Financial Stress from Advanced to Emerging Economies." In World Economic Outlook. Washington D.C.: International Monetary Fund.

- - . 2011. "The Transmission of Financial Stress from Advanced to Emerging Economies." Emerging Markets Finance and Trade 47(2): 40-68. DOI:

10.2753/ree1540-496x4703s203

Banerjee, Piyali, Vladimir Arčabić, and Hyejin Lee. 2017. "Fourier ADL Cointegration Test to Approximate Smooth Breaks with New Evidence from Crude Oil Market." Economic Modelling 67: 114-24. DOI: 10.1016/j.econmod.2016.11.004

Basher, Syed A., Alfred A. Haug, and Perry Sadorsky. 2012. "Oil Prices, Exchange Rates and Emerging Stock Markets.” Energy Economics 34(1): 227-40. DOI: 10.1016/j.eneco.2011.10.005
Basher, Syed A., Alfred A. Haug, and Perry Sadorsky. 2018. "The Impact of Oil-market Shocks on Stock Returns in Major Oil-exporting Countries." Journal of International Money and Finance 86: 264-80. DOI: 10.1016/j.jimonfin.2018.05.003

Bastianin, Andrea, and Matteo Manera. 2018. "How Does Stock Market Volatility React to Oil Price Shocks?" Macroeconomic Dynamics 22(3): 666-82. DOI: 10.1017/s1365100516000353

Broadstock, David C., and George Filis. 2014. "Oil Price Shocks and Stock Market Returns: New Evidence from the United States and China." Journal of International Financial Markets, Institutions and Money 33: 417-33. DOI: 10.1016/j.intfin.2014.09.007

Cardarelli, Roberto, Selim Elekdag, and Subir Lall. 2009. "Financial Stress, Downturns, and Recoveries." No. 2009-2100. International Monetary Fund. DOI: $10.5089 / 9781451872477.001$

- - - 2011. "Financial Stress and Economic Contractions." Journal of Financial Stability 7(2): 78-97. DOI: 10.1016/j.jfs.2010.01.005

Cashin, Paul, Kamiar Mohaddes, and Mehdi Raissi. 2017. "China's Slowdown and Global Financial Market Volatility: Is World Growth Losing Out?" Emerging Markets Review 31: 164-75. DOI: 10.1016/j. ememar.2017.05.001

Chen, Wang, Shigeyuki Hamori, and Takuji Kinkyo. 2014. "Macroeconomic Impacts of Oil Prices and Underlying Financial Shocks." Journal of International Financial Markets, Institutions and Money 29: 1-12. DOI: 10.1016/j.intfin.2013.11.006 
Dai, Wei, and Apostolos Serletis. 2018. "Oil Price Shocks and the Credit Default Swap Market." Open Economies Review 29(2): 283-93. DOI: 10.1007/ s11079-017-9454-Z

Das, Debojyoti, Vaneet Bhatia, Jayarethanam Pillai, and Aviral Kumar Tiwari. 2018. "The Relationship between Oil Prices and US Economy Revisited." Energy Sources, Part B: Economics, Planning, and Policy 13(1): 37-45. DOI: 10.1080/15567249.2017.1403497

Dickey, David A., and Wayne A. Fuller. 1981. "Likelihood Ratio Statistics for Autoregressive Time Series with a Unit Root." Econometrica 49(4): 1057-72. DOI: 10.2307/1912517

El-Shal, Amira. 2012. "The Spillover Effects of the Global Financial Crisis on Economic Activity in Emerging Economies - Investigating the Egyptian Case Using the Financial Stress Index." Economic Research Forum Working Papers (No. 737), December.

Enders, Walter, and Junsoo Lee. 2012a. "A Unit Root Test Using a Fourier Series to Approximate Smooth Breaks." Oxford Bulletin of Economics and Statistics 74(4): 574-99. DOI: 10.1111/j.1468-0084.2011.00662.x

- - . 2012b. "The Flexible Fourier Form and Dickey-Fuller Type Unit Root Tests." Economics Letters 117(1): 196-9. DOI: 10.1016/j. econlet.2012.04.081

Fang, Chung-Rou, and Shih-Yi You. 2014. "The Impact of Oil Price Shocks on the Large Emerging Countries' Stock Prices: Evidence from China, India and Russia." International Review of Economics \& Finance 29: 330-8. DOI: 10.1016/j.iref.2013.06.005
Gupta, Rangan, and Mampho P. Modise. 2013. "Does the Source of Oil Price Shocks Matter for South African Stock Returns? A Structural VAR Approach." Energy Economics 40: 825-31. 10.1016/j. eneco.2013.10.005

Hamilton, James D. 1983. "Oil and the Macroeconomy since World War II." Journal of Political Economy 91(2): 228-48. DOI: $10.1086 / 261140$

Hendry, David F., and Katarina Juselius. 2001. "Explaining Cointegration Analysis: Part II." The Energy Journal 22(1): 75-120. DOI: 10.5547/ issn0195-6574-ej-vol22-no1-4

$\mathrm{Hu}$, Chunyan, Xinheng Liu, Bin Pan, Bin Chen, and Xiaohua Xia. 2018. "Asymmetric Impact of Oil Price Shock on Stock Market in China: A Combination Analysis Based on SVAR Model and NARDL Model." Emerging Markets Finance and Trade 54(8): 1693705. DOI: 10.1080/1540496x.2017.1412303

Illing, Mark, and Ying Liu. 2003. An Index of Financial Stress for Canada. Bank of Canada (No. 2003-14).

Kang, Wensheng, and Ronald A. Ratti. 2015. "Oil Shocks, Policy Uncertainty and Stock Returns in China." Economics of Transition 23(4): 657-76. DOI: 10.1111/ecot.12062

Kang, Wensheng, Fernando Perez de Gracia, and Ronald A. Ratti. 2017. "Oil Price Shocks, Policy Uncertainty, and Stock Returns of Oil and Gas Corporations." Journal of International Money and Finance 70: 344-59. DOI: 10.1016/j. jimonfin.2016.10.003 
Kilian, Lutz. 2009. "Not All Oil Price Shocks Are Alike: Disentangling Demand and Supply Shocks in the Crude Oil Market." American Economic Review 99(3): 1053-69. DOI: 10.1257/aer.99.3.1053

Kilian, Lutz, and Daniel P. Murphy. 2012. "Why Agnostic Sign Restrictions Are Not Enough: Understanding the Dynamics of Oil Market VAR Models." Journal of the European Economic Association 10(5): 1166-88. DOI: 10.1111/j.1542-4774.2012.01080.x

Kilian, Lutz, and Cheolbeom Park. 2009. "The Impact of Oil Price Shocks on the US Stock Market." International Economic Review 50(4): 1267-87. DOI: 10.1111/j.1468-2354.2009.00568.x

Kilian, Lutz, and Zhou, Xiaoqing. 2020. "The Econometrics of Oil Market VAR Models." CESifo Working Paper Series 8153, CESifo. DOI: 10.24149/ wp2006

Kling, John L. 1985. "Oil Price Shocks and Stock Market Behavior." The Journal of Portfolio Management 12(1): 34-9. DOI: 10.3905/ jpm.1985.409034

Lütkepohl, Helmut. 1991. Introduction to Multiple Time Series Analysis. Heidelberg: Springer Verlag. DOI: 10.1007/978-3-662-02691-5

MacKinnon, James G. 1996. "Numerical Distribution Functions for Unit Root and Cointegration Tests." Journal of Applied Econometrics 11: 601-18. DOI: 10.1002/(sici)1099-1255(199611)11:6\%3C601::aidjae417\%3E3.0.co;2-t

Morana, Claudio. 2013. "Oil Price Dynamics, Macro-finance Interactions and the Role of Financial
Speculation." Journal of Banking \& Finance 37(1): 206-26. DOI: 10.1016/j.jbankfin.2012.08.027

Nazlioglu, Saban, Ugur Soytas, and Rangan Gupta. 2015. "Oil Prices and Financial Stress: A Volatility Spillover Analysis." Energy Policy 82: 278-288. DOI: 10.1016/j.enpol.2015.01.003

Park, Cyn-Young, and Rogelio V. Mercado Jr. 2014. "Determinants of Financial Stress in Emerging Market Economies." Journal of Banking \& Finance 45: 199-224. DOI: 10.1016/j.jbankfin.2013.09.018

Qadan, Mahmoud, and Hazar Nama. 2018. "Investor Sentiment and the Price of Oil." Energy Economics 69: 42-58. DOI: 10.1016/j.eneco.2017.10.035

Rehman, Mobeen Ur. 2018. "Do Oil Shocks Predict Economic Policy Uncertainty?" Physica A: Statistical Mechanics and its Applications 498: 123-36. DOI: 10.1016/j.physa.2017.12.133

Wan, Jer-Yuh, and Chung-Wei Kao. 2015. "Interactions between Oil and Financial Markets - Do Conditions of Financial Stress Matter?" Energy Economics 52: 160-75. DOI: 10.1016/j. eneco.2015.10.003

Wang, Yudong, Chongfeng Wu, and Li Yang. 2013. "Oil Price Shocks and Stock Market Activities:

Evidence from Oil-importing and Oil-exporting Countries." Journal of Comparative Economics 41(4): 1220-39. DOI: 10.1016/j.jce.2012.12.004

Yiu, Matthew S., Wai-Yip Alex Ho, and Lu Jin. "A Measure of Financial Stress in Hong Kong Financial Market - The Financial Stress Index." Hong Kong Monetary Authority Research Note 2, no. 2010 (2010): 0-2. 


\section{Notes}

(1) 
Notes

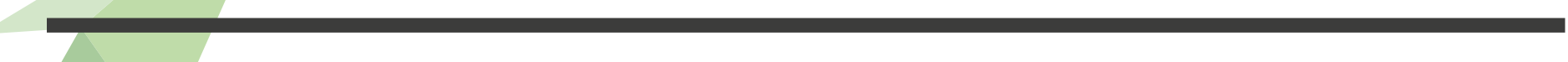




\section{Notes}

(1) 


\section{About the Authors}

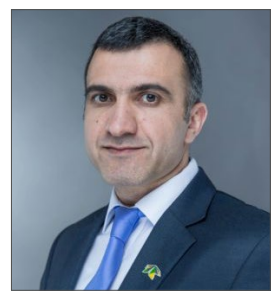

\section{Fakhri J. Hasanov}

Fakhri Hasanov is a senior research fellow and leads the KAPSARC Global Energy Macroeconometric Model (KGEMM) project. He was previously an associate professor and director of the Center for Socio-Economic Research at Qafqaz University, Azerbaijan. He holds a Ph.D. in econometrics from Azerbaijan State University of Economics and completed his post-doctoral work and study at George Washington University. His research interests and experience span econometric modeling and forecasting, time series and panel data econometrics, building and the application of macroeconometric models for policy analyses, with a particular focus on countries rich in natural resources, energy economics and environmental economics.

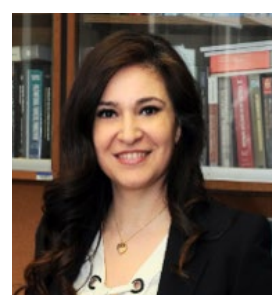

\section{Leila Dagher}

Dr. Leila Dagher is an Associate Professor of Economics at the American University of Beirut (AUB). She previously served as the Director of the Institute of Financial Economics (AUB), chaired the Department of Economics (AUB), and has been an adjunct lecturer at the George Washington University (GWU) since 2016. Dr. Dagher's research is at the nexus of energy, environment, and economics. Using econometrics tools, she studies various aspects of the environmental and energy sectors. Her research is frequently presented at international conferences, such as the ASSA and the WEAI annual conferences, and has appeared in The Energy Journal, Energy Policy, Energy Economics, and other leading peer-reviewed journals. Dr. Dagher has been a visiting scholar at Harvard's Kennedy School of Government, GWU, Virginia Tech, UCLA, and the National Renewable Energy Lab in Golden, Colorado. She holds a Bachelor of Engineering from the American University of Beirut and a Ph.D. in Mineral Economics from the Colorado School of Mines.

\section{About the Project}

This study was part of the KGEMM Policy and Research Studies project. This project produces policy and research studies that can provide Saudi Arabian decision-makers with a better understanding of national and international macroeconomic-energy relationships. The studies under the project mainly use KGEMM, an energy sector augmented general equilibrium macroeconomietric model as a tool. Some of the studies also use partial equilibrium models such as VAR/VEC where relevant. 
INAPSARC

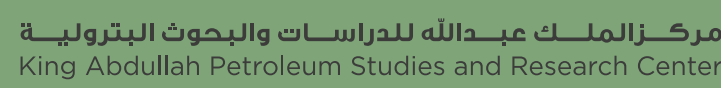

www.kapsarc.org 